\title{
Carbon Monoxide as a Signaling Molecule in Plants
}

\author{
Meng Wang and Weibiao Liao* \\ College of Horticulture, Gansu Agricultural University, Lanzhou, China
}

Carbon monoxide (CO), a gaseous molecule, has emerged as a signaling molecule in plants, due to its ability to trigger a series of physiological reactions. This article provides a brief update on the synthesis of $\mathrm{CO}$, its physiological functions in plant growth and development, as well as its roles in abiotic stress tolerance such as drought, salt, ultraviolet radiation, and heavy metal stress. CO has positive effects on seed germination, root development, and stomatal closure. Also, CO can enhance plant abiotic stress resistance commonly through the enhancement of antioxidant defense system. Moreover, CO shows cross talk with other signaling molecules including NO, phytohormones (IAA, ABA, and GA) and other gas signaling molecules $\left(\mathrm{H}_{2} \mathrm{~S}, \mathrm{H}_{2}, \mathrm{CH}_{4}\right)$.

OPEN ACCESS

Edited by:

Sylvain Jeandroz, AgroSup Dijon, France

Reviewed by:

John Hancock,

University of the West of England, Bristol, UK

Gaurav Zinta,

Shanghai Center for Plant Stress

Biology, China

*Correspondence:

Weibiao Liao

liaowb@gsau.edu.cn

Specialty section:

This article was submitted to

Plant Physiology,

a section of the journal

Frontiers in Plant Science

Received: 23 February 2016

Accepted: 13 April 2016

Published: 29 April 2016

Citation:

Wang M and Liao W (2016) Carbon Monoxide as a Signaling Molecule in Plants. Front. Plant Sci. 7:572. doi: 10.3389/fpls.2016.00572
Keywords: abiotic stress, carbon monoxide (CO), growth and development, antioxidant defense, physiological role, signaling transduction

\section{INTRODUCTION}

Carbon monoxide (CO), which has long been widely considered as a poisonous gas ("the silent killer") since 17th century, is a low molecular weight diatomic gas that occurs ubiquitously in nature. However, $\mathrm{CO}$ has been recently proven to be one of the most essential cellular components regulating a variety of biological processes both in animals and plants (Xie et al., 2008). Generally speaking, $\mathrm{CO}$ arises in biological systems principally during heme degradation as the oxidation product of the $\alpha$-methene bridge of heme, and this process is catalyzed by heme oxygenase enzymes (HOs, EC 1.14.14.18; Bilban et al., 2008). CO plays a critical role as neurotransmitter (Boehning et al., 2003), inhibitor of platelet aggregation (Brüne and Ullrich, 1987) and suppressor of acute hypertensive (Motterlini et al., 1998) in animals. Similarly, involvement of CO gas in different biological processes has also been found in plants. For instance, it acts as a compound with hormonal effects, affecting seed germination (Dekker and Hargrove, 2002), root development (Cui et al., 2015), and inducing stomatal closure (Cao et al., 2007a). In natural environments, plants develop inducible defence systems to survive biotic and abiotic threats, thus producing a wide variety of defense-related hormones to unlock the defense-related regulatory networks. CO is also generated against oxidant damage under abiotic stress, such as drought stress (Liu et al., 2010), salt stress (Ling et al., 2009), and heavy metal stress (Meng et al., 2011). In addition, CO not only acts as a signaling molecule during plant growth and development, but also interacts with other signaling molecules in plant stress response, growth and development (Santa-Cruz et al., 2010; Lin et al., 2014; Xie et al., 2014). In view of the evidence described above, we provide a brief update here on $\mathrm{CO}$ synthesis, physiological function in plant growth and development and its response to abiotic stresses. Furthermore, the cross-talk between $\mathrm{CO}$ and other signaling molecules including phytohormone, hydrogen peroxide $\left(\mathrm{H}_{2} \mathrm{O}_{2}\right)$, and other small gas signaling molecules is also discussed. 


\section{SYNTHESIS OF CO IN PLANTS}

Carbon monoxide is primarily generated by incomplete combustion of organic materials in atmosphere, and it is also a significant component of tobacco smoke and vehicle exhaust fumes (Figure 1). In animals and plants, the generation of intracellular $\mathrm{CO}$ and its actions are closely connected with HOs. As shown in Figure 1, HOs catalyze the oxidative conversion of heme to $\mathrm{CO}$, free iron $\left(\mathrm{Fe}^{2+}\right)$, and biliverdin (BV) in presence of molecular oxygen and electrons supplied by NADPH (Bilban et al., 2008). BV is then converted to the potent antioxidant bilirubin (BR) by biliverdin reductase. To date, three isoforms of $\mathrm{HO}$ have been detected in animals, including HO1 (32 kDa), $\mathrm{HO} 2(36 \mathrm{kDa}$ ), and HO3 (33 kDa) (Maines, 1997). HO1 is the highly inducible isozyme which increases rapidly to diverse stimuli and protects tissues against a wide range of injuries (Ryter and Choi, 2015). HO2 and HO3 are constitutively expressed with very low activity. Although the most investigated mechanism for $\mathrm{CO}$ production in animals involves HOs, much smaller amounts of $\mathrm{CO}$ can derive from other sources, like lipid peroxidation (Vreman et al., 2001; Figure 1).

In plants, the presence of $\mathrm{CO}$ biosynthesis was first reported by Wilks (1959) and subsequently the photoproduction of CO in living plants was also identified (Schade et al., 1999; Figure 1). Furthermore, Muramoto et al. (2002) found a plastid heme oxygenase (AtHO1) recombinant protein which was able to catalyze the formation of $\mathrm{CO}$ from heme molecules in vitro. To date, HOs are still viewed as the main enzymatic source of $\mathrm{CO}$ in plants (Xuan et al., 2008; Figure 1). Recent researches provided exciting evidence that the genes for HOs have been identified in a variety of plant species (Emborg et al., 2006; Wang et al., 2014). It comprises a small family with four members in total, which can be classified into two sub-families: HY1 (HO1), HO3 and $\mathrm{HO} 4$ all belong to the HO1 sub-family, while $\mathrm{HO} 2$ is the only number of the HO2 sub-family (Shekhawat and Verma, 2010). All members of the HO1 sub-family (HY1, HO3, and HO4) can convert heme to $\mathrm{BV}$ with a concomitant release of $\mathrm{CO}$ and $\mathrm{Fe}^{2+}$, whereas $\mathrm{HO} 2$ sub-family does not exhibit $\mathrm{HO}$ activity (Figure 1). Despite the enzymatically catalyzed reaction by $\mathrm{HOs}$ has been considered as the main productive route of $\mathrm{CO}$ in plants, the opposite results have been proposed in soybean (Zilli et al., 2014). The authors suggested that HOs are not the main source of CO in soybean plants, and lipid peroxidation and ureide metabolism could also be considered as potential sources of CO (Figure 1). Additionally, heme methylene bridges could be broken and $\mathrm{CO}$ released when exogenous $\mathrm{H}_{2} \mathrm{O}_{2}$ or ascorbic acid was supplied (Dulak and Józkowicz, 2003; Figure 1). Collectively, CO synthetic is a complex physiological process and more non-enzymatic biosynthetic processes of $\mathrm{CO}$ need to be elucidated.

\section{ROLE OF CO IN PLANT GROWTH AND DEVELOPMENT}

A high level of exogenous $\mathrm{CO}$ is toxic in plants and animals, however, $\mathrm{CO}$ at a proper level involves in many important physiological processes as an active signaling mediator. In animals, the amazing progress in our understanding of the biology of $\mathrm{CO}$ has developed rapidly. It was convincingly reported that exogenous $\mathrm{CO}$ gas could exert the beneficial effects on modulating a number of physiological events including neurotransmission (Boehning et al., 2003), vasodilation (Motterlini, 2007), and platelet aggregation (Brüne and Ullrich, 1987). More importantly, application of exogenous CO is

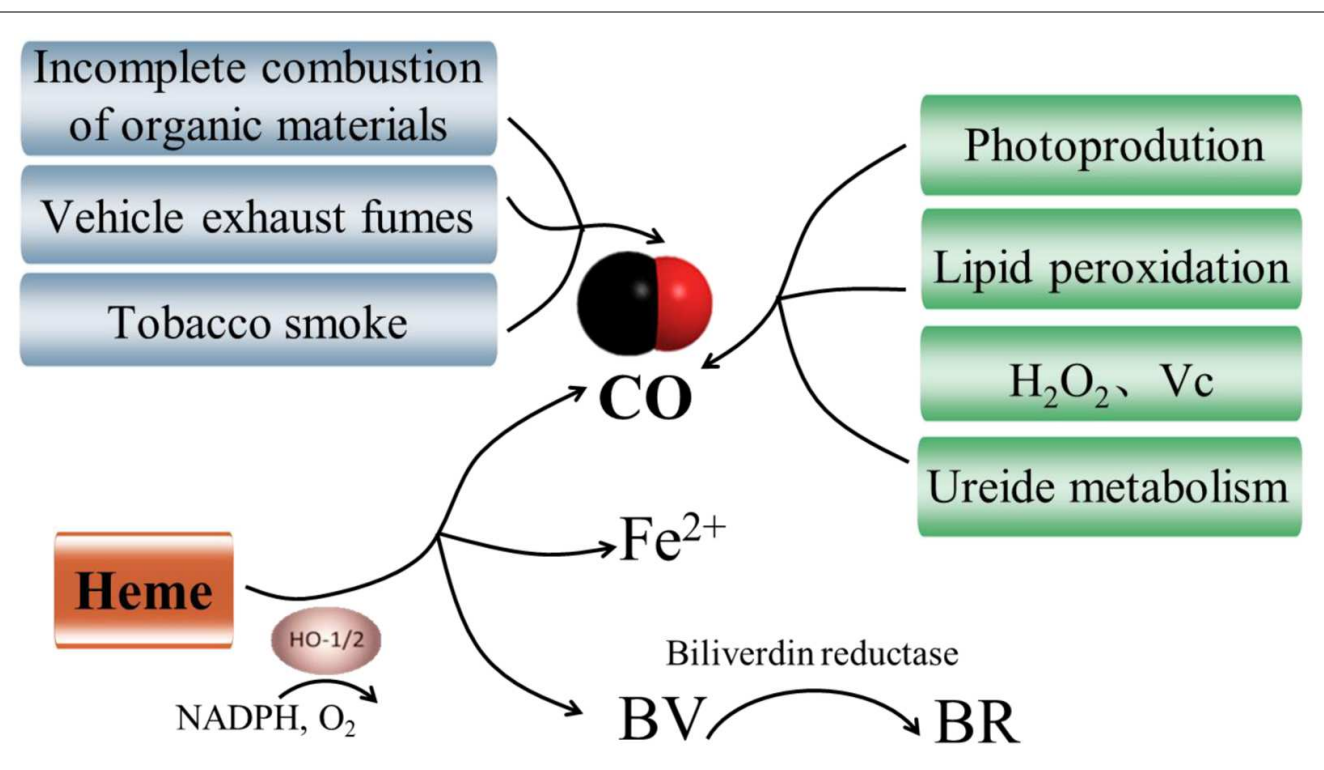

FIGURE 1 | Pathways of generation of carbon monoxide (CO). There are three synthetic routes for CO. Heme source is viewed as the main productive route of $\mathrm{CO}$ in animals and plants (Bilban et al., 2008). CO is also generated via incomplete combustion of organic materials, tobacco smoke and vehicle exhaust fumes in atmosphere. Additionally, non-heme sources including photoproduction (Schade et al., 1999), lipid peroxidation ( $\left(\mathrm{illi}\right.$ et al., 2014), hydrogen peroxide ( $\left.\mathrm{H}_{2} \mathrm{O}_{2}\right)$ and ascorbic acid (Vc; Dulak and Józkowicz, 2003), and ureide metabolism have been proposed in plants (Zilli et al., 2014). 
developing a new therapeutic strategy for treatment of numerous clinical conditions (Fagone et al., 2015). Also in plants, CO has been studied to elucidate the roles of this enigmatic signaling molecule in plant growth and development. Accumulating evidence in plants has shown that $\mathrm{CO}$ is used for a number of intercellular and intracellular biological functions. For instance, $\mathrm{CO}$ was likely to delay gibberellins (GA)-triggered programmed cell death $(\mathrm{PCD})$ in wheat aleurone cells by up-regulating of ascorbate peroxidase (APX) and catalase (CAT) expression, and decreasing $\mathrm{H}_{2} \mathrm{O}_{2}$ overproduction (Wu et al., 2010; Table 1). Until now, the studies of roles of $\mathrm{CO}$ in plants mostly focus on seed germination, root development, and stomatal closure.

\section{Seed Germination}

Seed germination, which is a highly specialized phase in plant life, is essential for seedling establishment. It is a critical step in a plant's life cycle and is regulated by a wide range of endogenous and environment factors (Kong et al., 2015). Several researches demonstrated that $\mathrm{CO}$ exerted an advantageous effect on promoting seed germination in a dose-dependent manner and in many plants. The application of low levels of exogenous CO $(0.1$ or $1 \%)$ stimulated seed germination of foxtail (Setaria faberi) under favorable temperature and moisture conditions, while germination decreased with the addition of $75 \% \mathrm{CO}$ due to the inhibition of mitochondrial respiration (Dekker and Hargrove, 2002; Table 1). Both CO donor heme and CO aqueous dose-dependently accelerated the physiological process of seed germination in Oryza sativa via activating amylase activity and increasing the formation of energy resources (Liu et al., 2007; Table 1). Similarly, $\mathrm{CO}$ as a positive regulator was also involved in the process of seed germination in wheat (Liu et al., 2010) and Brassica nigra (Amooaghaie et al., 2015; Table 1).

\section{Root Development}

The root systems have been identified to play important roles in plant nutrient and water acquisition. $\mathrm{CO}$ has exhibited positive effects on regulating plant root development. For example, the promoting effects of auxin (IAA) or nitric oxide (NO) on root elongation were mimicked by application of aqueous solution of $\mathrm{CO}$ with different saturations in wheat seedlings (Xuan et al., 2007; Table 1). In tomato, exogenous CO promoted root hair density and elongation, which increased 3.38- and 2.48-folds compared with the control. Genetic analyses have shown that CO was able to affect the root hair formation by up-regulating LeExt1 gene expression (Guo et al., 2009; Table 1). Actually, previous studies of CO-induced root development mostly concentrated on lateral root (LR) and adventitious root (AR).

\section{LR Development}

Lateral root is derived from the pericycle of parent root, in which mature cells are stimulated to dedifferentiate and proliferate to form a LR primordium, finally leading to the emergence of LR. LR plays an indispensable role in the development of plant root system responsible for water-use efficiency and the extraction of nutrients from soils (Guo et al., 2008). CO has been shown to induce the formation of LR. In rapeseed seedlings, the total length and number of LR increased significantly in a dosedependent manner with the $\mathrm{CO}$ donor hematin or $\mathrm{CO}$ aqueous, while the positive effects were fully reversed by the addition of the CO scavenger hemoglobin $(\mathrm{Hb})$ or the $\mathrm{CO}$-specific synthetic inhibitor zinc protoporphyrin-IX (ZnPPIX; Cao et al., 2007b; Table 1). Treatment with exogenous CO up-regulated heme oxygenase-1 (LeHO-1) expression and the amount of LeHO-1 proteins, then stimulated the formation of tomato LR (Guo et al., 2008; Table 1). Above results indicate that exogenous $\mathrm{CO}$ is, at least partially, correlated with the formation process of LR in plants.

\section{AR Development}

Adventitious root development is an essential step for vegetative propagation which involves the reestablishment of a meristematic tissue after removal of the primary root system (Liao et al., 2012). AR formation is affected by multiple endogenous and

TABLE 1 | Overview of CO-mediated physiological processes in plants.

\begin{tabular}{|c|c|c|c|c|}
\hline Physiological process & Plant species & Tissue & $\begin{array}{l}\text { CO-induced } \\
\text { effect }\end{array}$ & Reference \\
\hline \multirow[t]{4}{*}{ Seed germination } & Setaria faberii & \multirow[t]{4}{*}{ Seed } & \multirow[t]{4}{*}{+} & Dekker and Hargrove, 2002 \\
\hline & Oryza sativa & & & Liu et al., 2007 \\
\hline & Triticum aestivum & & & Liu et al., 2010 \\
\hline & Brassica nigra & & & Amooaghaie et al., 2015 \\
\hline \multirow[t]{2}{*}{ Lateral root formation } & Solanum lycopersicum & \multirow[t]{2}{*}{ LR } & \multirow[t]{2}{*}{+} & Guo et al., 2008 \\
\hline & Brassica napus & & & Cao et al., 2007b \\
\hline \multirow[t]{5}{*}{ Adventitious root development } & Cucumis sativus & \multirow[t]{5}{*}{ AR } & \multirow[t]{5}{*}{+} & Xuan et al., 2008 \\
\hline & Phaseolus radiates & & & Xu J. et al., 2006 \\
\hline & Cucumis sativus & & & Cui et al., 2015 \\
\hline & Cucumis sativus & & & Lin et al., 2014 \\
\hline & Cucumis sativus & & & Xuan et al., 2012 \\
\hline Root hair development & Solanum lycopersicum & Root hair & + & Guo et al., 2009 \\
\hline Root elongation & Triticum aestivum & Root tip segments & + & Xuan et al., 2007 \\
\hline Programmed cell death & Triticum aestivum & Aleurone layers & - & Wu et al., 2010 \\
\hline Stomatal closure & Vicia faba & Leaf & + & $\begin{array}{l}\text { Cao et al., 2007a; She and } \\
\text { Song, 2008; Song et al., } 2008\end{array}$ \\
\hline
\end{tabular}


exogenous factors, wherein IAA is viewed as one of the most important phytohormones in mediating AR (Xuan et al., 2008). The investigation of $\mathrm{CO}$-induced $\mathrm{AR}$ formation can be dated back to the year 2006 that $\mathrm{CO}$ exhibited positive effects on AR formation in mung bean seedling (Xu J. et al., 2006; Table 1). Then, more attention has been given to highlight AR formation induced by CO. Xuan et al. (2008) discovered that CO dosedependently promoted AR number and length in IAA-depleted cucumber seedlings by up-regulating the expression of target genes (CSDNAJ-1 and CSCDPK1/5) during AR (Table 1). It has also been demonstrated that the induction of AR formation by methane-rich water (MRW) was blocked by ZnPPIX, and further reversed by $\mathrm{CO}$ aqueous (Cui et al., 2015; Table 1). In addition, CO could up-regulate NO production, and thereafter promoting AR formation in IAA-depleted seedlings (Xuan et al., 2012; Table 1). Previous results also exposed that endogenous HO-1 might be involved in hydrogen-rich water (HRW)induced AR formation in cucumber explants (Lin et al., 2014; Table 1). Thus, HRW or NO-induced AR formation may require the involvement of $\mathrm{CO}$ (Xuan et al., 2012; Lin et al., 2014).

\section{Stomatal Closure}

Stomatal movement critically controls the plant water status, and it can be triggered by numerous environment or hormonal factors. Among these, the stress hormone abscisic acid (ABA) is a key player in regulating stomatal movement under drought and humidity stress (Grondin et al., 2015). ABA treatment was found to increase $\mathrm{CO}$ content and $\mathrm{HO}$ activity in vicia faba leaves, and then researchers began to investigate the relationship between $\mathrm{CO}$ and stomatal closure. Interestingly, further results showed that exogenously applied hematin and $\mathrm{CO}$ aqueous not only resulted in the enhancement of $\mathrm{CO}$ release, but also induced stomatal closure in dose- and time-dependent manners (Cao et al., 2007a; Table 1). The CO effects in stomatal movement are similar to $\mathrm{NO}$ and $\mathrm{H}_{2} \mathrm{O}_{2}$ (She and Song, 2008; Song et al., 2008; Table 1).

\section{RESPONSE OF CO IN ABIOTIC STRESS}

Abiotic stresses are major constraint to plant growth, survival, yield, and distribution, which also result in the oxidative stress and reactive oxygen species (ROS) overproduction by disrupting cellular redox homeostasis. It has been known that $\mathrm{ABA}$ is a key regulator involved in plant developmental processes and responses to biotic and abiotic stresses (Raghavendra et al., 2010). Similar to ABA, CO is also required for the alleviation of abiotic stress-induced oxidative stress (Cao et al., 2007a).

\section{Salt Stress}

Salt stress has become an ever-present threat to crop yields often causing many unfortunate consequences in plants, such as growth inhibition, ionic phyto-toxicity and ROS overproduction. Low concentrations of CO alleviated the inhibition of seed germination and the damage of seedling leaves produced by salt stress through enhancing antioxidant enzyme activities including superoxide dismutase (SOD), CAT, APX, and guaiacol peroxidase (GPOX) in wheat (Huang et al., 2006; Xu S. et al., 2006; Table 2). Similar result was confirmed in rice. CO enhanced the activities of CAT and SOD and

TABLE 2 | Overview of the responses of $\mathrm{CO}$ in abiotic stress.

\begin{tabular}{|c|c|c|c|c|c|c|}
\hline Plant species & Tissue & $\begin{array}{l}\text { Abiotic } \\
\text { stress }\end{array}$ & CO-mediated effect & $\begin{array}{l}\text { CO-mediated } \\
\text { antioxidant enzyme }\end{array}$ & CO-mediated gene & Reference \\
\hline Triticum aestivum & Seed & Drought & $\begin{array}{l}\text { Maintain antioxidative } \\
\text { capability/ROS-scavenging } \\
\text { activity }\end{array}$ & CAT, APX, SOD, DHAR & $\mathrm{HO}-1$ & Liu et al., 2010 \\
\hline Triticum aestivum & Seed & Salt & Counteract lipid peroxidation & CAT, APX, SOD, GPOX & - & Xu S. et al., 2006 \\
\hline Triticum aestivum & Leaf & Salt & Alleviate oxidative damage & CAT, APX, SOD, GPOX & - & Huang et al., 2006 \\
\hline Oryza sativa & Seed & Salt & Alleviate oxidative damage & CAT, SOD & HO-1,CAT, SOD, APX & Liu et al., 2007 \\
\hline Triticum aestivum & Root & Salt & $\begin{array}{l}\text { Maintain ion } \\
\text { homeostasis/up-regulate } \\
\text { antioxidant defense }\end{array}$ & $\begin{array}{l}\text { APX, GR, SOD, } \\
\text { MDHAR, DHAR }\end{array}$ & $S O D, G R, D H A R$ & Xie et al., 2008 \\
\hline Triticum aestivum & Root & Salt & $\begin{array}{l}\text { Inhibition superoxide anion } \\
\text { overproduction }\end{array}$ & SOD & $S O D$ & Ling et al., 2009 \\
\hline Cassia obtusifolia & $\begin{array}{l}\text { Seeds/ } \\
\text { seedlings }\end{array}$ & Salt & $\begin{array}{l}\text { Increase osmotic } \\
\text { substances/antioxidant enzyme } \\
\text { activities }\end{array}$ & SOD, POD, CAT, APX & - & Zhang et al., 2012 \\
\hline Glycine max & Leaf & UVB & Prevent oxidative stress & CAT, APX & $\mathrm{HO}-1$ & Yannarelli et al., 2006 \\
\hline Medicago sativa & Root & $\mathrm{Hg}$ & Alleviate oxidative damage & GR, MDHAR, SOD & $\mathrm{HO}-1 / 2$ & Han et al., 2007 \\
\hline Chlamydomonas reinhardtii & - & $\mathrm{Hg}$ & $\begin{array}{l}\text { Suppress reactive oxygen } \\
\text { species }\end{array}$ & SOD, CAT, APX & $\mathrm{HO}-1$ & Wei et al., 2011 \\
\hline Brassica juncea & Root & $\mathrm{Hg}$ & Alleviate oxidative stress & SOD, POD, CAT, APX & $S O D, P O D, C A T, A P X$ & Meng et al., 2011 \\
\hline Medicago sativa & Root & $\mathrm{Cd}$ & Alleviate oxidative damage & SOD, POD, APX, GR & $H O-1, A P X, G R$ & Han et al., 2008 \\
\hline Chlamydomonas reinhardtii & - & $\mathrm{Cu}$ & Alleviate oxidative damage & SOD, CAT, APX & $S O D, C A T, A P X$ & Zheng et al., 2011 \\
\hline Arabidopsis & - & $\mathrm{Fe}$ & Maintain iron-homeostasis & - & $\mathrm{HO}-1$ & Kong et al., 2010 \\
\hline
\end{tabular}


up-regulated the expression of CAT and $\mathrm{Cu} / \mathrm{Zn}$-SOD genes, thus resulting in alleviating salt-induced oxidative damage and finally decreasing the inhibition of seed germination (Liu et al., 2007; Table 2). CO might increase the tolerance of wheat seedling to salt stress, and its alleviation of PCD and root growth inhibition was linked to the maintenance of ion homeostasis and the decrease of superoxide anion $\left(\mathrm{O}_{2}{ }^{-}\right)$overproduction (Xie et al., 2008; Ling et al., 2009; Table 2). In Cassia obtusifolia, hematin or CO-saturated aqueous solution increased the level of cytosolic osmotic substances (total soluble sugars, free proline, and soluble protein) and antioxidant enzyme activities (SOD, POD, CAT, and APX), and lightened the damage of photosynthetic system under salt stress, consequently alleviating the inhibition of seed germination and seedling growth deriving from salinity stress (Zhang et al., 2012; Table 2).

\section{Drought Stress}

Drought stress is a widely present environmental factor which affects negatively on seed germination, seedling growth and even plant productivity. Application of exogenous hematin brought about marked increase in the activities of amylase and antioxidant enzyme such as CAT, APX, SOD, and dehydroascorbate reductase (DHAR), which were responsible for the mitigation of drought stress-induced wheat seed germination inhibition and lipid peroxidation (Liu et al., 2010; Table 2). To date, the investigations of $\mathrm{CO}$ in plant tolerance to drought stress are scarce.

\section{Ultraviolet Radiation Stress}

The stratospheric ozone layer is thinning resulting in more ultraviolet-B (UV-B) radiation reaching the surface of the earth. UV-B exposure increases the amount of ROS and oxygen-derived free radicals, thus leading to cellular damage and apoptosis. $\mathrm{UV}-\mathrm{B}$ radiation provoked an increase of the expression of $\mathrm{HO}$ 1 and its transcript levels in a dose-dependent manner, which was regarded as a cell protection mechanism against UV-B radiation-induced oxidative damage (Yannarelli et al., 2006). Moreover, $\mathrm{CO}$ production was closely related with $\mathrm{HO}$-mediated heme catabolism, implying that $\mathrm{CO}$ probably exerted potential functions in modulating the defense response of plants to UV-B stress (Yannarelli et al., 2006; Table 2).

\section{Heavy Metals Stress}

Heavy metals such as mercury $(\mathrm{Hg})$, cadmium $(\mathrm{Cd})$, iron $(\mathrm{Fe})$, and copper $(\mathrm{Cu})$ result in serious environmental pollution in many places worldwide and lead to a threat to human health and plant development. Heavy metal-induced oxidative stress in plants could be attenuated in the presence of small reactive gaseous molecules such as NO. Like NO, the vital role of $\mathrm{CO}$ in relieving heavy metals stress in plants has been verified (Han et al., 2007; Zheng et al., 2011). Hematin and $\mathrm{CO}$ supplementation to $\mathrm{HgCl}_{2}$-treated alfalfa root reduced lipid peroxidation and increased root elongation via activating antioxidant enzymes including glutathione reductase (GR), monodehydroascorbate reductase (MDHRR) and SOD activities, as well as decreasing lipoxygenase activity (LOX;
Han et al., 2007; Table 2). CO also enhanced the tolerance of algae to $\mathrm{Hg}$ exposure which was closely related to the lower accumulation of $\mathrm{Hg}$ and free radical species (Wei et al., 2011; Table 2). The detrimental effect by $\mathrm{Hg}$ stress could be partially reversed by administration of $\mathrm{CO}$ in Indian mustard through suppressing the production of $\mathrm{O}_{2}{ }^{-}$and $\mathrm{H}_{2} \mathrm{O}_{2}$ and increasing the accumulation of proline (Meng et al., 2011; Table 2). Also, Cd-induced oxidative damage was alleviated by $\mathrm{CO}$ pretreatment via modulating glutathione metabolism in alfalfa, which accelerated the exchange of oxidized glutathione (GSSG) to glutathione (GSH) to restore GSH: GSSG ration and further decreased the oxidative damage (Han et al., 2008; Table 2). In addition, $\mathrm{Cu}$-induced oxidative damage in algae was alleviated by CO mainly via the improvement of CAT activity (Zheng et al., 2011; Table 2). Moreover, the up-regulating expression of genes related to $\mathrm{Fe}$ acquisition such as AtlRT1, AtFRO2, AtF1T1, and AtFER1 by CO were responsible for preventing the Fe deficient-induced chlorosis and improving chlorophyll accumulation (Kong et al., 2010; Table 2).

\section{CROSS-TALK BETWEEN CO AND OTHER SIGNALING MOLECULES}

Carbon monoxide has been highly appreciated for its versatile properties as a signaling molecule regulating diverse physiological processes in animals and plants. A number of studies have shown that CO signal transduction is extremely complex which usually doesn't operate as the linear pathways but that extensive cross-talk occurs between various signal transduction. Thus, we provide here a brief overview of the interaction between $\mathrm{CO}$ signaling molecule and other signaling molecules.

\section{Cross-talk between $\mathrm{CO}$ and $\mathrm{NO}$}

Carbon monoxide signal transduction pathways don't always work independently, but it is rather closely linked to NO. The two endogenously produced gasses share many common downstream signaling pathways and have some similar properties. For example, $\mathrm{CO}$ in animals, like $\mathrm{NO}$, binded to the iron atom of heme proteins of soluble guanylate cyclase (sCG) to activate the enzyme and increase intracellular second messenger cyclic guanosine monophosphate (cGMP) production, thus exerting many of their biological functions including regulating vascular tone, inhibiting platelet aggregation, and decreasing blood pressure (Snyder et al., 1998). However, whether the phenomenon exists in plants still has no sufficient evidence to confirm. CO was also able to mimic to some extent the effect of NO in dose-dependently inducing stomatal closure (Song et al., 2008) and K-to-Na ration (Xie et al., 2008). Increasing evidence in animals supports that there exist an intimate connection in the expression of $\mathrm{HO}$ and NOS responsible for generating $\mathrm{CO}$ and $\mathrm{NO}$, indicating possible interaction between the $\mathrm{CO}-$ and NO-generating systems. Also, it is becoming increasingly clear that $\mathrm{CO}$ can potentiate the activity of NO synthase (NOS) in plants. Song et al. (2008) implied that there might be existing 
HO-1 enzyme and NOS-like enzyme activity in $V$. faba guard cells. CO was involved in darkness-induced NO synthesis via the NOS-like enzyme (Song et al., 2008; Figure 2). NaCl-treated wheat seedling roots resulted in a moderate enhancement of endogenous NO level, whereas a very strong increase of NO appeared when adding 50\% CO-saturated aqueous solution (Xie et al., 2008; Figure 2). Conversely, CO could directly bind to and inactivate NOS, decreasing the enzyme activity probably due to the competition of $\mathrm{CO}$ with $\mathrm{NO}$ for binding to its targets such as sCG (Ding et al., 1999). Interesting, recent research showed that NOS enzymes only exist in a few algal species but appear to not be conserved in land plants, suggesting the production of NO may rely mainly on nitrate assimilation in land plants (Jeandroz et al., 2016). Thus, NO synthesis is a complex process in plants and the interaction between the $\mathrm{CO}$ - and NO-generating systems via NOS enzymes also needs further validation. Furthermore, a functional interaction of $\mathrm{NO}$ and $\mathrm{CO}$ has been demonstrated in regulating plant growth and development. For example, $\mathrm{CO}$ alleviated osmotic-induced wheat seed germination inhibition and lipid peroxidation which required participation of NO (Liu et al., 2010; Figure 2). Santa-Cruz et al. (2010) proposed that NO was implicated in the $\mathrm{HO}$ signaling pathway which might directly potentiate UV-B-induced HO-1 transcription in soybean plants. Meanwhile, NO might act as a downstream signal molecule in hemin-induced cucumber AR process (Xuan et al., 2012; Figure 2).

\section{Cross-talk between $\mathrm{CO}$ and Phytohormone}

It has been demonstrated that $\mathrm{CO}$ may partially involve in IAA-induced tomato LR development via altering biosynthesis/perception in some way (Guo et al., 2008; Figure 2). Meanwhile, Xuan et al. (2008) strongly confirmed that there exists a serial linkage $\mathrm{IAA} \rightarrow \mathrm{HO} / \mathrm{CO} \rightarrow \mathrm{AR}$. IAA could activate $\mathrm{HO} / \mathrm{CO}$ signaling system, and then triggered the signal transduction events, thus leading to AR formation in cucumber (Figure 2). Also, CO might be involved in ABAinduced stomatal closure which $\mathrm{NO}$ and cGMP may function as downstream intermediates in $\mathrm{CO}$ signal transduction network (Cao et al., 2007a; Figure 2). In addition, $\mathrm{HO} / \mathrm{CO}$ might be a component or signaling system of hydrogen sulfide $\left(\mathrm{H}_{2} \mathrm{~S}\right)$ induced cytoprotective role against GA-induced PCD (Xie et al., 2014; Figure 2). Thus, phytohormone could induce various distinct developmental responses in plants, which are dependent on CO.

\section{Cross-talk between $\mathrm{CO}$ and Other Small Signaling Molecules}

Similar to $\mathrm{NO}, \mathrm{H}_{2} \mathrm{O}_{2}$, and other small signaling molecules also play an indispensable role in CO-mediated physiological responses. She and Song (2008) directly illustrated for the first time that $\mathrm{CO}$-induced stomatal closure probably was mediated by $\mathrm{H}_{2} \mathrm{O}_{2}$ signaling pathways in $V$. faba (Figure 2). Up-regulation of $\mathrm{HO}$ expression protected aleurone layers against GA-induced PCD in wheat implicating an alteration of $\mathrm{H}_{2} \mathrm{O}_{2}$ metabolism (Wu et al., 2010; Figure 2). There is adequate evidence to support

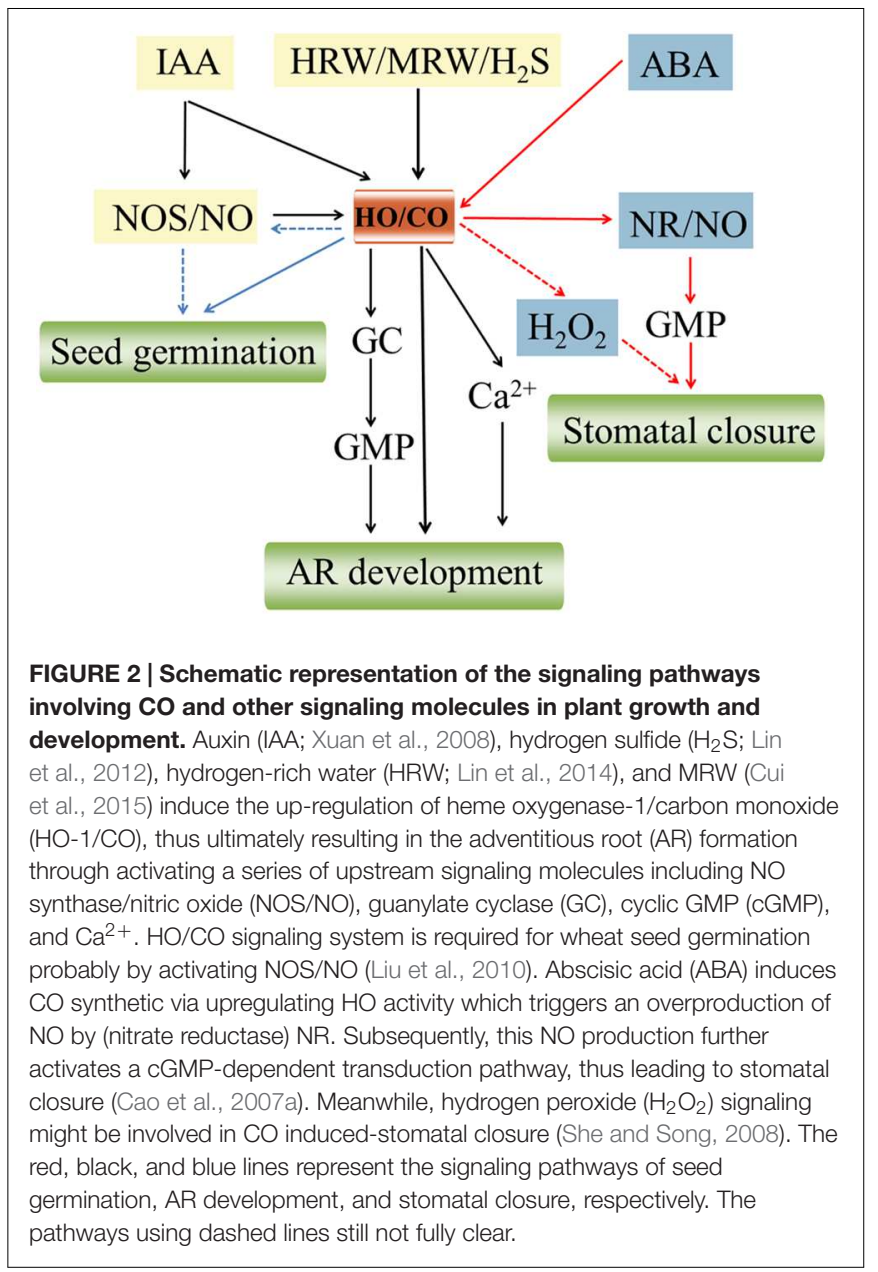

that $\mathrm{HO} / \mathrm{CO}$ signaling system mediating cucumber AR formation interacts closely with $\mathrm{H}_{2} \mathrm{~S}, \mathrm{H}_{2}$, and $\mathrm{CH}_{4}$. For example, $\mathrm{HO}-1$ as a downstream component was involved in $\mathrm{H}_{2} \mathrm{~S}$-induced $\mathrm{AR}$ cucumber formation through the modulation of expression of DNAJ-1 and CDPK1/5 genes (Lin et al., 2012; Figure 2). Likewise, $\mathrm{HRW}$-induced AR formation was heme oxygenase-1/ CO (HO$1 / \mathrm{CO}$ )-dependent by up-regulating target genes related to auxin signaling and AR formation including CsDNAJ-1, CsCDPK1/5, CsCDC6, and CsAUX22B/D (Lin et al., 2014; Figure 2). More recently, it was suggested that MRW might serve as a stimulator of $\mathrm{AR}$, which was partially mediated by $\mathrm{HO}-1 / \mathrm{CO}$ and $\mathrm{Ca}^{2+}$ pathways (Cui et al., 2015; Figure 2).

\section{CONCLUSION}

Carbon monoxide as a gaseous signaling molecule is well studied in animals, but the current situation of $\mathrm{CO}$ research in plants is at an early stage. Despite the presence of CO biosynthesis in plants was first reported by Wilks (1959) and HO was claimed as its main productive route, the experimental evidence of nonenzymatic biosynthetic processes of $\mathrm{CO}$ is still quite limited. $\mathrm{CO}$ has been recognized as a signal or bio-effector involved in plant 
growth and development under normal and stress conditions. CO can enhance plant abiotic stress resistance in relation to the cross-talk with other signaling molecules, but the exact biological roles of $\mathrm{CO}$ in plants and its detail signal transduction pathway are largely unknown. Thus, more work need to be done to further elucidate the above questions by using pharmacological, physiological, and molecular approaches in the future.

\section{AUTHOR CONTRIBUTIONS}

All authors listed, have made substantial, direct and intellectual contribution to the work, and approved it for publication.

\section{REFERENCES}

Amooaghaie, R., Tabatabaei, F., and Ahadi, A. M. (2015). Role of hematin and sodium nitroprusside in regulating Brassica nigra seed germination under nanosilver and silver nitrate stresses. Ecotox. Environ. Safe. 113, 259-270. doi: 10.1016/j.ecoenv.2014.12.017

Bilban, M., Haschemi, A., Wegiel, B., Chin, B.Y., Wagner, O., and Otterbein, L.E. (2008). Heme oxygenase and carbon monoxide initiate homeostatic signaling. J. Mol. Med. 86, 267-279. doi: 10.1007/s00109-007-0276-0

Boehning, D., Moon, C., Sharma, S., Hurt, K. J., Hester, L. D., Ronnett, G. V., et al. (2003). Carbon monoxide neurotransmission activated by CK2 phosphorylation of heme oxygenase-2. Neuron 40, 129-137. doi: 10.1016/S0896-6273(03)00596-8

Brüne, B., and Ullrich, V. (1987). Inhibition of platelet aggregation by carbon monoxide is mediated by activation of guanylate cyclase. Mol. Pharmacol. 32, 497-504

Cao, Z. Y., Huang, B. K., Wang, Q. Y., Xuan, W., Ling, T. F., Zhang, B., et al. (2007a). Involvement of carbon monoxide produced by heme oxygenase in ABA-induced stomatal closure in Vicia faba and its proposed signal transduction pathway. Chinese Sci. Bull. 52, 2365-2373. doi: 10.1007/s11434007-0358-y

Cao, Z.Y., Xuan, W., Liu, Z.Y., Li, X.N., Zhao, N., Xu, P., et al. (2007b). Carbon monoxide promotes lateral root formation in rapeseed. J. Integr. Plant Biol. 49, 1070-1079. doi: 10.1111/j.1672-9072.2007.00482.x

Cui, W. T., Qi, F., Zhang, Y. H., Cao, H., Zhang, J., Wang, R., et al. (2015). Methane-rich water induces cucumber adventitious rooting through heme oxygenase1/carbon monoxide and $\mathrm{Ca}^{2+}$ pathways. Plant Cell Rep. 34, 435-445. doi: 10.1007/s00299-014-1723-3

Dekker, J., and Hargrove, M. (2002). Weedy adaptation in Setaria spp.V. Effects of gaseous environment on giant foxtail (Setaria faberii) (Poaceae) seed germination. Am. J. Bot. 89, 410-416. doi: 10.3732/ajb. 89.3.410

Ding, Y., McCoubrey, W. K. Jr., and Maines, M. D. (1999). Interaction of heme oxygenase- 2 with nitric oxide donors. Is the oxygenase an intracellular 'sink' for NO? Eur. J. Biochem. 264, 854-861. doi: 10.1046/j.1432-1327.1999. 00677.x

Dulak, J., and Józkowicz, A. (2003). Carbon monoxide: a "new" gaseous modulator of gene expression. Acta. Biochim. Pol. 50, 31-48.

Emborg, T. J., Walker, J. M., Noh, B., and Vierstra, R. D. (2006). Multiple heme oxygenase family members contribute to the biosynthesis of the phytochrome chromophore in Arabidopsis. Plant Physiol. 140, 856-868. doi: 10.1104/pp.105.074211

Fagone, P., Mangano, K., Mammana, S., Cavalli, E., Marco, R. D., and Barcellona, M. L, et al. (2015). Carbon monoxide-releasing molecule-A1 (CORM-A1) improves clinical signs of experimental autoimmune uveoretinitis (EAU) in rats. Clin. Immunol. 157, 198-204. doi: 10.1016/j.clim.2015.02.002

Grondin, A., Rodrigues, O., Verdoucq, L., Merlot, S., Leonhardt, N., and Maurel, C. (2015). Aquaporins contribute to ABA-triggered stomatal closure through OST1-mediated phosphorylation. Plant Cell 27, 1945-1954. doi: $10.1105 /$ tpc.15.00421

\section{ACKNOWLEDGMENTS}

We thank Dr. Claudio Pasian (The Ohio State University, Columbus, OH, USA) for critical reading of the manuscript. This research was supported by the National Natural Science Foundation of China (Nos. 31160398 and 31560563), the Post Doctoral Foundation of China (Nos. 20100470887 and 2012T50828), the Key Project of Chinese Ministry of Education (No. 211182), the Research Fund for the Doctoral Program of Higher Education (No. 20116202120005), the Natural Science Foundation of Gansu Province, China (Nos. 1308RJZA179 and 1308RJZA262), the Fundamental Research Funds for Universities in Gansu, P. R. China.

Guo, K., Kong, W. W., and Yang, Z. M. (2009). Carbon monoxide promotes root hair development in tomato. Plant Cell Environ. 32, 1033-1045. doi: 10.1111/j.1365-3040.2009.01986.x

Guo, K., Xia, K., and Yang, Z. M. (2008). Regulation of tomato lateral root development by carbon monoxide and involvement in auxin and nitric oxide. J. Exp. Bot. 59, 3443-3452. doi: 10.1093/jxb/ern194

Han, Y., Xuan, W., Yu, T., Fang, W. B., Lou, T. L., Gao, Y., et al. (2007). Exogenous hematin alleviates mercury-induced oxidative damage in the roots of Medicago sativa. J. Integr. Plant Bio. 49, 1703-1713. doi: 10.1111/j.17447909.2007.00592.x

Han, Y., Zhang, J., Chen, X. Y., Gao, Z. Z., Xuan, W., Xu, S., et al. (2008). Carbon monoxide alleviates cadmium-induced oxidative damage by modulating glutathione metabolism in the roots of medicago sativa. New Phytol. 177, 155-166. doi: 10.1111/j.1469-8137.2007.02251.X

Huang, B. K., Xu, S., Xuan, W., Li, M., Cao, Z. Y., Liu, K. L., et al. (2006). Carbon monoxide alleviates salt-induced oxidative damage in wheat seedling leaves. J. Integr. Plant Biol. 48, 249-254. doi: 10.1111/j.1744-7909.2006. 00220.x

Jeandroz, S., Wipf, D., Stuehr, D. J., Lamattina, L., Melkonian, M., Tian, Z., et al. (2016). Occurrence, structure, and evolution of nitric oxide synthase-like proteins in the plant kingdom. Sci. Signal. 417, re2. doi: 10.1126/scisignal.aad4403

Kong, D. D., Ju, C. L., Parihar, A., Kim, S., Cho, D., and Kwak, J. M. (2015). Arabidopsis glutamate receptor homolog3.5 modulates cytosolic $\mathrm{Ca}^{2+}$ level to counteract effect of abscisic acid in seed germination. Plant Physiol. 167, 1630-1642. doi: 10.1104/pp.114.251298

Kong, W. W., Zhang, L. P., Guo, K., Liu, Z. P., and Yang, Z. M. (2010). Carbon monoxide improves adaptation of arabidopsis to iron deficiency. Plant Biotechnol. J. 8, 88-99. doi: 10.1111/j.1467-7652.2009.00469.x

Liao, W. B., Zhang, M. L., Huang, G. B., and Yu, J. H. (2012). $\mathrm{Ca}^{2+}$ and CaM are involved in $\mathrm{NO}$ - and $\mathrm{H}_{2} \mathrm{O}_{2}$-induced adventitious root development in marigold. J. Plant Growth Regul. 31, 253-264. doi: 10.1007/s00344-011-9235-7

Lin, Y. T., Li, M. Y., Cui, W. T., Lu, W., and Shen, W. B. (2012). Haem oxygenase-1 is involved in hydrogen sulfide-induced cucumber adventitious root formation. J. Plant Growth Regul. 31, 519-528. doi: 10.1007/s00344-012-9262-Z

Lin, Y. T., Zhang, W., Qi, F., Cui, W. T., Xie, Y. J., and Shen, W. B. (2014). Hydrogen-rich water regulates cucumber adventitious root development in a heme oxygenase-1/carbon monoxide-dependent manner. J. Plant Physiol. 171, 1-8. doi: 10.1016/j.jplph.2013.08.009

Ling, T. F., Zhang, B., Cui, W. T., Wu, M. Z., Lin, J. S., and Zhou, W. T. (2009). Carbon monoxide mitigates salt-induced inhibition of root growth and suppresses programmed cell death in wheat primary roots by inhibiting superoxide anion overproduction. Plant Sci. 177, 331-340. doi: 10.1016/j.plantsci.2009.06.004

Liu, K. L., Xu, S., Xuan, W., Ling, T. F., Cao, Z. Y., Huang, B. K., et al. (2007). Carbon monoxide counteracts the inhibition of seed germination and alleviates oxidative damage caused by salt stress in Oryza sativa. Plant Sci. 172, 544-555. doi: 10.1016/j.plantsci.2006.11.007

Liu, Y. H., Xu, S., Ling, T. F., Xu, L. L., and Shen, W. B. (2010). Heme oxygenase/carbon monoxide system participates in regulating wheat seed 
germination under osmotic stress involving the nitric oxide pathway. J. Plant Physiol. 167, 1371-1379. doi: 10.1016/j.jplph.2010.05.021

Maines, M. D. (1997). The heme oxygenase system: a regulator of second messenger gases. Annu. Rev. Pharmacol. 37, 517-554. doi: 10.1146/annurev.pharmtox.37.1.517

Meng, D. K., Chen, J., and Yang, Z. M. (2011). Enhancement of tolerance of Indian mustard (Brassica juncea) to mercury by carbon monoxide. J. Hazard. Mater. 186, 1823-1829. doi: 10.1016/j.jhazmat.2010.12.062

Motterlini, R. (2007). Carbon monoxide-releasing molecules (CO-RMs): vasodilatory, anti-ischaemic and anti-inflammatory activities. Biochem. Soc. T. 35, 1142-1146. doi: 10.1042/BST0351142

Motterlini, R., Gonzales, A., Foresti, R., Clark, J. E., Green, C. J., and Winslow, R. M. (1998). Heme oxygenase-1 derived carbon monoxide contributes to the suppression of acute hypertensive responses in vivo. Circ. Res. 83, 568-577. doi: 10.1161/01.RES.83.5.568

Muramoto, T., Tsurui, N., Terry, M. J., Yokota, A., and Kohchi, T. (2002). Expression and biochemical properties of a ferredoxin-dependent heme oxygenase required for phytochrome chromophore synthesis. Plant Physiol. 130, 1958-1966. doi: 10.1104/pp.008128

Raghavendra, A. S., Gonugunta, V. K., Christmann, A., and Grill, E. (2010). ABA perception and signaling. Trends Plant Sci. 15, 395-401. doi: 10.1016/j.tplants.2010.04.006

Ryter, S. W., and Choi, A. M. K. (2015). Targeting heme oxygenase-1/carbon monoxide for therapeutic modulation of inflammation. Transl. Res. 167, 7-34. doi: 10.1016/j.trsl.2015.06.011

Santa-Cruz, D. M., Pacienza, N. A., Polizio, A. H., Balestrasse, K. B., Tomaro, M. L., and Yannarelli, G. G. (2010). Nitric oxide synthaselike dependent no production enhances heme oxygenase up-regulation in ultraviolet-B-irradiated soybean plants. Phytochemistry 71, 1700-1707. doi: 10.1016/j.phytochem.2010.07.009

Schade, G. W., Hofmann, R. W., and Crutzen, P. J. (1999). CO emissions from degrading plant matter. Tellus. B. 51, 889-908. doi: 10.1034/j.16000889.1999.t01-4-00003.x

She, X. P., and Song, X. G. (2008). Carbon monoxide-induced stomatal closure involves generation of hydrogen peroxide in Vicia faba guard cells. J. Integr. Plant Biol. 50, 1539-1548. doi: 10.1111/j.1744-7909.2008.00716.x

Shekhawat, G. S., and Verma, K. (2010). Haem oxygenase (HO): an overlooked enzyme of plant metabolism and defence. J. Exp. Bot. 61, 2255-2270. doi: 10.1093/jxb/erq074

Snyder, S. H., Jaffrey, S. R., and Zakhary, R. (1998). Nitric oxide and carbon monoxide: parallel roles as neural messengers. Brain Res. Rev. 26, 167-175. doi: 10.1016/S0165-0173(97)00032-5

Song, X. G., She, X. P., and Zhang, B. (2008). Carbon monoxide-induced stomatal closure in vicia faba is dependent on nitric oxide synthesis. Physiol. Plant. 132, 514-525. doi: 10.1111/j.1399-3054.2007.01026.x

Vreman, H. J., Wong, R. J., and Stevenson, D. K. (2001). "Sources, sinks and measurement of carbon monoxide," in Carbon Monoxide and Cardiovascular Functions, ed. R. Wang (Boca Raton, FL: CRC Press LLC), 273-307.

Wang, L. J., Ma, F., Xu, S., Zheng, T. Q., Wang, R., Chen, H. P., et al. (2014). Cloning and characterization of a heme oxygenase-2 gene from rice (Oryza sativa L.), and its expression analysis in response to some abiotic stresses. Acta Physiol. Plant. 36, 893-902. doi: 10.1007/s11738-013-1468-6

Wei, Y. Y., Zheng, Q., Liu, Z. P., and Yang, Z. M. (2011). Regulation of tolerance of Chlamydomonas reinhardtii to heavy metal toxicity by heme oxygenase-1 and carbon monoxide. Plant Cell Physiol. 52, 1665-1675. doi: 10.1093/pcp/pcr102

Wilks, S. S. (1959). Carbon monoxide in green plants. Science 129, 964-966. doi: 10.1126/science.129.3354.964

Wu, M. Z., Huang, J. J., Xu, S., Ling, T. F., Xie, Y. J., and Shen, W. B. (2010). Haem oxygenase delays programmed cell death in wheat aleurone layers by modulation of hydrogen peroxide metabolism. J. Exp. Bot. 62, 235-248. doi: $10.1093 /$ jxb/erq261

Xie, Y. J., Ling, T. F., Han, Y., Liu, K. L., Zheng, Q. S., Huang, L. Q., et al. (2008). Carbon monoxide enhances salt tolerance by nitric oxide-mediated maintenance of ion homeostasis and up-regulation of antioxidant defence in wheat seedling roots. Plant Cell Environ. 31, 1864-1881. doi: 10.1111/j.13653040.2008.01888.x

Xie, Y. J., Zhang, C., Lai, D. W., Sun, Y., Samma, M. K., Zhang, J., et al. (2014). Hydrogen sulfide delays GA-triggered programmed cell death in wheat aleurone layers by the modulation of glutathione homeostasis and heme oxygenase-1 expression. J. Plant Physiol. 171, 53-62. doi: 10.1016/j.jplph.2013.09.018

Xu, J., Xuan, W., Huang, B. K., Zhou, Y. H., Ling, T. F., Xu, S., et al. (2006). Carbon monoxide-induced adventitious rooting of hypocotyl cuttings from mung bean seedling. Chinese Sci. Bull. 51, 668-674. doi: 10.1007/s11434-0060668-5

Xu, S., Sa, Z., Cao, Z. S., Xuan, W., Huang, B. K., Ling, T. F., et al. (2006). Carbon monoxide alleviates wheat seed germination inhibition and counteracts lipid peroxidation mediated by salinity. J. Integr. Plant Biol. 48, 1168-1176. doi: 10.1111/j.1744-7909.2006. 00337.x

Xuan, W., Huang, L. Q., Li, M., Huang, B. K., Xu, S., Liu, H., et al. (2007). Induction of growth elongation in wheat root segments by heme molecules: a regulatory role of carbon monoxide: a regulatory role of carbon monoxide in plants? Plant Growth Regul. 52, 41-51. doi: 10.1007/s10725-007-9175-1

Xuan, W., Xu, S., Li, M. Y., Han, B., Zhang, B., Zhang, J., et al. (2012). Nitric oxide is involved in hemin-induced cucumber adventitious rooting process. J. Plant Physiol. 169, 1032-1039. doi: 10.1016/j.jplph.2012. 02.021

Xuan, W., Zhu, F. Y., Xu, S., Huang, B. K., Ling, T. F., Qi, J. Y., et al. (2008). The heme oxygenase/carbon monoxide system is involved in the auxininduced cucumber adventition rooting process. Plant Physiol. 148, 881-893. doi: 10.1104/pp.108.125567

Yannarelli, G. G., Noriega, G. O., Batlle, A., and Tomaro, M. L. (2006). Heme oxygenase up-regulation in ultraviolet-B irradiated soybean plants involves reactive oxygen species. Planta 224, 1154-1162. doi: 10.1007/s00425-0060297-x

Zhang, C. P., Li, Y. C., Yuan, F. G., Hu, S. J., and He, P. (2012). Effects of hematin and carbon monoxide on the salinity stress responses of cassia obtusifolia L. seeds and seedlings. Plant Soil. 359, 85-105. doi: 10.1007/s11104-0121194-7

Zheng, Q., Meng, Q., Wei, Y. Y., and Yang, Z. M. (2011). Alleviation of copperinduced oxidative damage in chlamydomonas reinhardtii by carbon monoxide. Arch. Environ. Con. Tox. 61, 220-227. doi: 10.1007/s00244-010-9602-6

Zilli, C. G., Santa-Cruz, D. M., and Balestrasse, K. B. (2014). Heme oxygenase-independent endogenous production of carbon monoxide by soybean plants subjected to salt stress. Environ. Exp. Bot. 102, 11-16. doi: 10.1016/j.envexpbot.2014.01.012

Conflict of Interest Statement: The authors declare that the research was conducted in the absence of any commercial or financial relationships that could be construed as a potential conflict of interest.

Copyright (C) 2016 Wang and Liao. This is an open-access article distributed under the terms of the Creative Commons Attribution License (CC BY). The use, distribution or reproduction in other forums is permitted, provided the original author(s) or licensor are credited and that the original publication in this journal is cited, in accordance with accepted academic practice. No use, distribution or reproduction is permitted which does not comply with these terms. 